\title{
The 8th KONA Award
}

The 8th KONA Award sponsored by Hosokawa Powder Technology Foundation and given to the scientists or groups who have achieved excellence in the researches related to the basic powder technology, was presented to Professor Yutaka Tsuji of Osaka University and to Professor Chikao Kanaoka of Kanazawa University by Masuo Hosokawa, President of the Foundation on January 25, 2000 at the R\&D Center of Hosokawa Micron Corporation in Hirakata.
Prof. Kanaoka's research achievements are related to studies on aerosol behavior and collection efficiency of aerosol.

Prof. Tsuji's research achievements are related to studies on computer simulation in the field of gassolid flows and in fluidized beds.

In these studies both professors obtained epochmaking results.
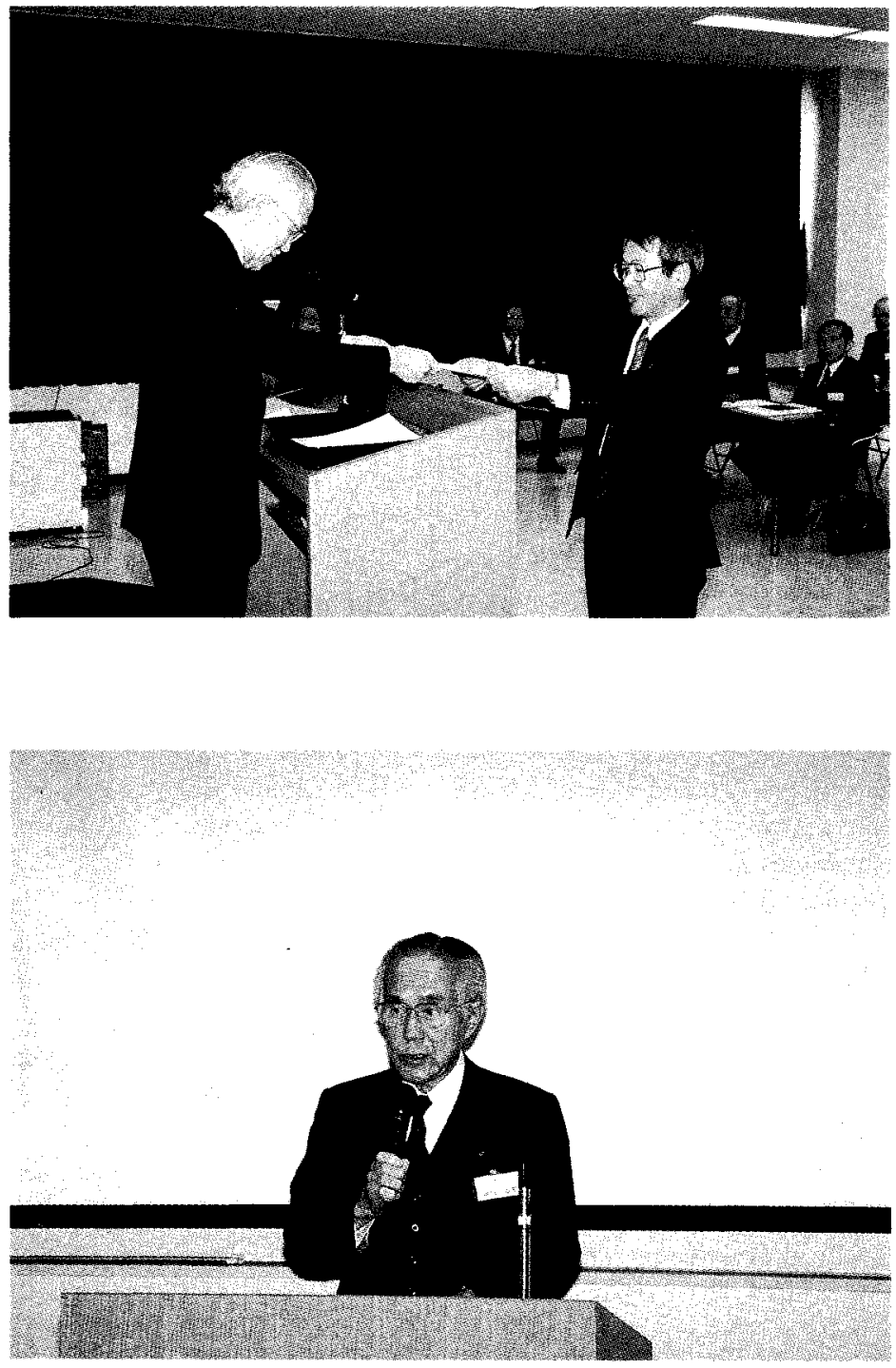